\title{
A New Paradigm for Clinical Investigation of Infectious Syndromes in Older Adults: Assessing Functional Status as a Risk Factor and Outcome Measure
}

\author{
Kevin High ${ }^{1}$, Suzanne Bradley ${ }^{2}$, Mark Loeb ${ }^{3}$, Robert Palmer ${ }^{4}$, Vincent Quagliarello ${ }^{5}$, \\ Thomas Yoshikawa ${ }^{6}$
}

\begin{abstract}
Adults aged 65 and over comprise the fastest growing segment of the U.S. population, and older adults experience greater morbidity and mortality due to infection than young adults. While this factor is well established, most clinical investigation of infectious diseases in the aged focuses on microbiology, and crude endpoints of clinical success such as cure rates or mortality, but often fails to assess functional status, a critical variable in geriatric care. Functional status can be evaluated as a risk factor for infectious disease or an outcome of interest following specific interventions utilizing well-validated instruments. This paper outlines the currently available data suggesting a link between infection, immunity and impaired functional status in the elderly, summarizes commonly employed instruments used to determine specific aspects of functional status, and provides recommendations for a new paradigm in which clinical trials of older adults include functional assessment. J Am Geriatr Soc 53:528-535, 2005.
\end{abstract}

Keywords: Aging, Functional Assessment, Infection, Clinical Research

\section{INTRODUCTION}

$\mathrm{T}$ he world is aging. Both industrialized and developing nations are experiencing a rapid growth in people aged

\footnotetext{
${ }^{1}$ Department of Internal Medicine, Sections of Infectious Diseases and Hematology/Oncology, Wake Forest University Health Sciences, Winston Salem, NC ${ }^{2}$ VA Medical Center, Department of Internal Medicine,

Division of Infectious Diseases, University of Michigan School of Medicine, Ann Arbor, MI ${ }^{3}$ Division of Infectious Diseases and Medical Microbiology, McMaster University and Hamilton Civic Hospitals, Hamilton, Ontario, Canada ${ }^{4}$ Section of Geriatric Medicine, Cleveland Clinic Foundation, Cleveland, $\mathrm{OH}^{5}$ Department of Internal Medicine, Infectious Diseases Section, Yale University School of Medicine, New Haven, CT ${ }^{6}$ Department of Internal Medicine, Charles R. Drew University of Medicine and Science, King-Drew Medical Center, Los Angeles, CA.

Contact Information for Corresponding Author: Medical Center Boulevard, Winston Salem, NC 27157-1042; Phone: 336-716-4584; Fax: 336-716-3825; Email: khigh@wfubmc.edu
}

65 years and older ${ }^{1}$. Infection is common in older adults however, despite the recognition of infection as a serious health problem in the elderly ${ }^{2-4}$, investigations of infectious syndromes in the aged often fail to address fundamental issues relevant to old and frail persons. Physical disability, cognitive and emotional impairment, quality of life, and social consequences critical to the older adult need to be included to fully assess the role these factors play in infection risk and outcome. Treatment studies in elderly patients may report on the usual parameters of clinical features, microbial etiologies, laboratory changes, radiological findings, clinical response, microbiological response, and mortality. While these parameters are important, they fail to indicate what has happened to the patient. A fundamental principle of geriatric research is inclusion of an assessment of the impact of disease on functional capacity and maintenance of independence. Does the patient return to the same level of function as before the infection? Can the patient still perform the basic functions of life such as dressing, eating, taking a bath, toileting, and walking? Did their cognitive function change during or after the infection? Has depression become clinically apparent and impacted the recovery of function? What were infectious and non-infectious complications, and did they differ from those seen in younger adults with the same infection? Was the length of hospital stay and cost of care higher than younger patients with a similar disease process? Was discharge to a place other than home (e.g. nursing home) required? These are many of the issues and questions that must be addressed in future infectious disease studies in older persons if we are truly to provide clinically meaningful data and information to clinicians, patients, and family caregivers.

This review briefly summarizes: the demography of aging, unique features of infection in an aging population, the underlying mechanisms of infection and inflammation that may alter functional status, commonly used instruments to measure functional status, and the current status of infectious diseases research with regard to functional assessment. A new governing paradigm for clinical studies that includes functional measures is suggested to answer the most clinically relevant questions in older adults with infection. 


\section{DEMOGRAPHICS OF AN AGING WORLD}

Through the early 20th century, the major causes of death in the United States were infectious diseases ${ }^{5}$, and life expectancy at birth was approximately 47 years $^{6}$. The reduction of infectious deaths related to antisepsis, vaccinations, antibiotics, and public health measures has now increased life expectancies in many industrialized nations to over 75 years; an aging population is the result. While this change in demographic took a century in most of Europe, the U.S., Japan and Canada, the same transformation is now occurring in the developing world and will lead to a doubling of the population aged 65 and older in countries such as Brazil, China, and Thailand in about 25 years ${ }^{1}$. As of 2000 , an estimated 420 million persons were aged 65 years and older; this represents an increase of 9.5 million over the previous year. At least 31 countries have 2 million older citizens or more, and that number is to double by 2030 with the greatest increases in developing countries ${ }^{1}$. Italy is the "oldest nation" with the greatest proportion of elderly $(18 \%)$ in the population. The United States, with an elderly population of $13 \%$, is not one of the top 25 oldest countries although by 2030 , it is estimated that $20 \%$ of the US population will be aged 65 years or older ${ }^{1,7}$. Most elderly persons will be women, representing $56 \%$ of adults $\geq$ age 65 , but women account for an increasing proportion of the oldest old (over age 85) ${ }^{7}$. The proportion of older adults who are members of a racial minority group is expected to increase from $11.3 \%$ to $16.5 \%$ over this time period ${ }^{7}$.

With increasing life expectancy, rates of chronic disease, disability, and health costs rise ${ }^{1,7}$. It is estimated that $80 \%$ of adults aged 65 years and older have at least one chronic health condition and $50 \%$ will have at least two conditions ${ }^{7}$. In developed countries, costs for health care for older adults have been reported to be 3-5 times greater than for younger adults; \$12,100 (in 1997 dollars) for every adult aged 65 years and older ${ }^{7}$.

Multiple co-morbid conditions can contribute to a decline in function, an inability to live independently, and a need for long-term care. The percent of older adults receiving institutionalized care vary from society to society; rates for Northern Europe, North America, and Japan approach $6-9 \%$. In the U.S., the life-time risk that a 65 year old will require some type of nursing home care is nearly $50 \%{ }^{8}$. In 1997, most nursing home residents $(75 \%)$ in the United States were women aged 85 years and older. In the last decade, costs to provide nursing home and home health care in the United States have doubled to a cost of $\$ 132$ billion $^{7}$.

Fortunately, the future of older adults is not entirely a pessimistic one. Recent studies suggest that healthcare interventions can postpone or reverse disability in older adults and improve quality of life ${ }^{7}$. The challenge for the Infectious Diseases community is to provide interventions that not only treat the microorganism, but demonstrate a return of older adults to baseline or improved levels of function.

\section{INFECTIONS IN THE ELDERLY: RISK FACTORS, CHARACTERISTICS, AND OUTCOMES}

Compared to younger adults, elderly individuals have unique predispositions to infectious diseases as a result of multiple risk factors. First, impairments in innate and adaptive immunity create risk for disease acquisition from specific infectious pathogens (e.g., Listeria monocytogenes, Streptococcus pneumoniae, Mycobacteria tuberculosis and varicella-zoster reactivation) $)^{9}$. Second, older adults have an increased prevalence of underlying co-morbid disease (e.g., diabetes, COPD, vascular disease) that foster risk for common community acquired disease including urinary tract infection, pneumonia, and soft tissue infection. Third, the increased prevalence of functional limitations with extremes of age (e.g., impaired swallowing and cough reflex), dwelling in crowded extended care facilities, and instrumentation with prosthetic devices (e.g., chronic bladder catheterization, implantable cardiac devices, artificial joints) leads to an increased risk for aspiration pneumonia, institutional-associated influenza and Clostridium difficile colitis, recurrent urinary tract infection, and prosthetic device infection ${ }^{10}$. The complexity of this population mandates that clinical research of infectious syndromes in older adults account for the multiple determinants of disease in the elderly ${ }^{11,12}$.

Physicians must be cognizant of these unique predispositions to infection among elderly adults and seek early recognition, diagnosis, and therapy. A challenge for early diagnosis is the often subtle and unique presentation of infections in elderly adults. For example, basal body temperatures in older adults may be lower than the standard mean of $37^{\circ} \mathrm{C}$ (or $\left.98.6^{\circ} \mathrm{F}\right)^{13,14}$; in one study of elderly nursing home residents, a single temperature of $101^{\circ} \mathrm{F}$ had a sensitivity of only $40 \%$ among those with infection ${ }^{15}$. Furthermore, common infections like pneumonia and urinary tract infection are less likely to present with classically recognized features (e.g., cough and sputum production, or dysuria), and more commonly present with a change in cognitive function (e.g., confusion) or physical function (e.g., inability to perform activities of daily living) ${ }^{16}$. This altered presentation is fostered by underlying sensory deficits (e.g., hearing and vision impairment) and dementia in the elderly host. Impaired vasopressin responses with age lead to dehydraton, hypernatremia, and azotemia when infection develops and also contribute to cognitive and functional decline $e^{17}$.

The subtle presentation of infection in older adults can have adverse consequences both for under-recognition of disease, and for over-use of empiric antibiotics. Because it is often difficult to distinguish true infection, over use of antibiotics is common, particularly in long-term care where $25-75 \%$ of antibiotic use has been found to be 'inappropriate', and strict adherence to minimum criteria for initiating antibiotics should be practiced ${ }^{18}$.

When infection does occur, systemic impairment in immune function, underlying co-morbidity, baseline functional deficits, and delayed recognition make elderly adults more prone to adverse outcomes. Compared to younger adults, case series and cohort studies have shown increased morbidity or mortality for older adults with a variety of infections including community acquired pneumonia ${ }^{19}$, bacteremia $^{20}$, infective endocarditis ${ }^{21}$, and HIV (even after adjustment for CD4 count at diagnosis) ${ }^{22}$. The precise contribution of underlying host predisposition (i.e., underlying co-morbidity or functional impairment) versus disease severity (i.e., related to immune deficits or delayed therapy) is difficult to discern from current data. 


\section{UNDERLYING MECHANISMS LINKING INFECTION, INFLAMMATION, AGING AND DISABILITY}

Chronic inflammatory conditions are often associated with high levels of circulating cytokines, such as TNF- $\alpha$, that induce muscle wasting and disability regardless of age, but this relationship may take on special meaning for older adults. Epidemiologic data suggest an association between chronic inflammation and a variety of adverse outcomes in older adults including death ${ }^{23-25}$ and disability ${ }^{26-32}$. Frailty, defined as a wasting syndrome accompanied by increased vulnerability to functional disability, morbidity and mortality ${ }^{33}$ is theorized to be exacerbated by 'trigger events' that enhance inflammation and play a central role in the development of functional limitations in the elderly (Figure 1).

Although waning immune responses in aged adults likely contribute to their risk of infection, not all facets of immunity are equally affected and some aspects of the immune response (e.g. innate inflammatory responses) are actually enhanced or prolonged with age ${ }^{34-37}$. In contrast to young adults, aged humans demonstrate inflammatory responses that are significantly prolonged after experimental administration of endotoxin ${ }^{36}$ or natural infection with common organisms such as $S$. pneumoniae ${ }^{35}$. Even syndromes typically felt to represent inconsequential 'colonization' in older adults, such as asymptomatic bacteriuria, can be associated with activation of inflammation as evidenced by higher levels of circulating inflammatory cytokines $^{38}$. Co-morbidities common in the aged may also be coupled with low-level inflammation and play an important role in disability. For example, mild depression is associated with an enhanced and prolonged inflammatory response after the relatively trivial stimulus of influenza vaccination in older adults ${ }^{39}$. Together, these data suggest there is an inability to appropriately down-regulate inflammation after infectious events in older adults, especially those with co-morbidity, and many investigators consider aging itself to be an inflammatory state ${ }^{40}$.

How might sub-acute or prolonged inflammation in older adults lead to disability? Aging is associated both with a loss of muscle mass termed sarcopenia (reduction in specific force) and a waning of contractile force of the muscle fibers that remain (reduction in absolute force) ${ }^{41}$. Both are linked to infection and inflammation (Figure 2), and loss of

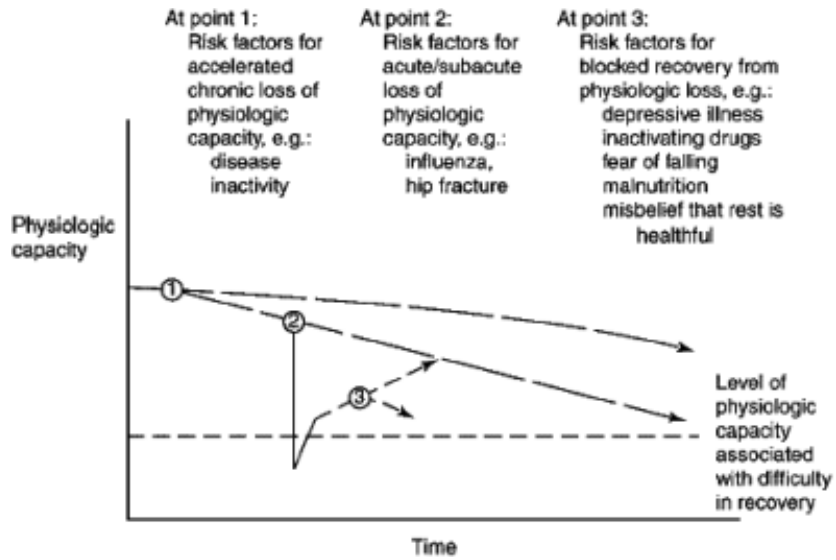

Figure 1. The role of trigger events in accelerating functional decline in older adults. Reprinted with permission from (32).

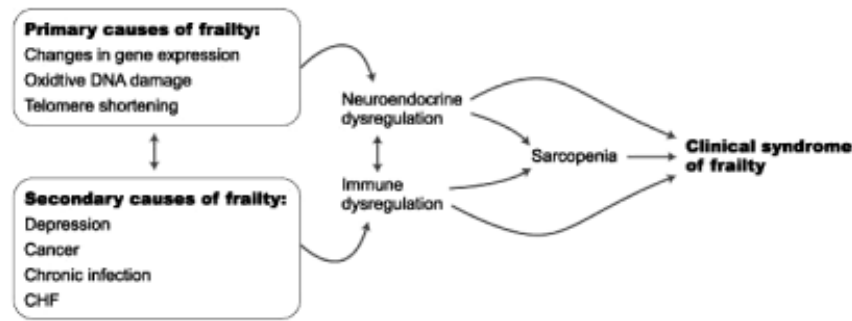

Figure 2. Hypothesized relationship between infection/inflammation and other risk factors that leads to sarcopenia and frailty. Reprinted from (81) with permission.

muscle strength is a robust, independent predictor of falls, disability, and mortality in older adults (reviewed in $\operatorname{ref}^{26}$ ). Inflammation is a direct cause of sarcopenia ${ }^{42-47}$ via cytokine-induced muscle cell dropout without regeneration of muscle fibers during the phase of convalescence. 'Notch' pathways that modulate self-renewal in a variety of tissues ${ }^{48,49}$ may be markedly impaired with age and play a prominent role in this failure ${ }^{50}$. Similarly, inflammation may contribute to age-related declines of absolute contractile force via pathways mediated by insulin-like growth factor-1 (IGF-1). IGF-1 strongly enhances both muscle regeneration $^{51}$ and muscle contractility via excitation-contraction coupling ${ }^{41}$, but IGF-1 expression and activity are blunted by inflammation. Even transient elevations in TNF$\alpha$ can inhibit IGF-1-mediated signaling over long periods of time ${ }^{52,53}$.

Taken together, the data summarized above suggests: ${ }^{1}$ there are strong epidemiologic links between infection, inflammation, reduced muscle mass and disability in older adults; ${ }^{2}$ biologically plausible pathways support a causal link, and ${ }^{3}$ interventions to prevent infection ('trigger events') or speed recovery from infectious illnesses and thereby blunt the inflammatory response in older adults have the potential to positively impact functional status.

\section{EVALUATING FUNCTIONAL STATUS IN PATIENTS AND CLINICAL TRIALS}

Functional status is defined in terms of basic and instrumental activities of daily living (BADL, IADL). BADL include the ability to independently bathe, dress, groom, eat, transfer from bed to chair, toilet and maintain continence. The more complex IADL tasks include the patient's ability to independently take medications, handle finances, perform household tasks, shop, use public transportation, and use a telephone. Loss of independence in the performance of BADL and IADL may occur during or after an infectious illness in older adults. ${ }^{54}$

\section{Prognostic importance}

Functional status has prognostic importance that is not always captured by measures of disease severity, co-morbidity, or diagnosis. In studies of hospitalized elderly patients, dependence in the performance of BADL is an independent predictor of mortality, nursing home placement, length of stay, and costs of medical care ${ }^{55,56}$. Nosocomial infection and severe functional impairment are stronger predictors of mortality than age alone in hospitalized patients, ${ }^{57}$, and in nursing home patients, baseline performance of BADL is 
the major determinant of survival following pneumonia ${ }^{58}$. These observations underscore the importance of including measures of functional status when evaluating outcomes of infectious disease therapies.

\section{Measures of Functional Status}

While many instruments to define functional status are available, we will specifically focus on those validated for study in older adults. Reliable instruments or scales are administered as self-reports, questionnaires or performancebased measures ${ }^{59}$. Global instruments capture functional status and items of health-related quality of life. The Medical Outcomes Study 36-item Short-Form Health Survey (SF-36) includes eight subscales: physical functioning (with 10 items), bodily pain, role limitations due to physical health problems, role limitations due to personal or emotional problems, general mental health, social functioning, vitality (energy/fatigue), and general health perceptions ${ }^{60}$. A modified SF-36 eases scoring (www.rand.org/health/surveys/sf36item/). The index of ADL and the physical selfmaintenance scale for BADL are widely used for clinical and research purposes when greater specificity of individual BADL and IADL items is desired (for example, when using ADL items as predictor or outcome variables ${ }^{61,62}$. The IADL scales are generally more sensitive than BADL to change over time ${ }^{62,63}$. The BADL and IADL scales are often adapted for use as self or proxy-reports. In rehabilitation studies the Barthel Index, ${ }^{64}$ and its derivative Functional Independence Measure, ${ }^{65}$ are sensitive and commonly used instruments with good scaling (wide range of values) properties.

\section{Performance-based measures of physical function}

Performance-based measures of gait, balance and mobility obtain information that is complementary to self-reports and ADL scales. A Short Physical Performance Battery that includes an assessment of standing balance, a timed 8-foot walk and a timed test of five repetitions of rising from a chair and sitting down, was shown in a cohort study to predict disability in ADL and mobility ${ }^{66}$. The Timed Up and Go test is a simple measure of the patient's gait speed: the patient is timed while rising from a chair, walking 10 feet, turning and returning to sit in the chair. ${ }^{67}$ The more comprehensive Performance Oriented Balance and Mobility Assessment rates the patient's gait initiation, turns, step length and height, step symmetry and continuity, path deviation, and trunk sway. ${ }^{68}$ The Physical Performance Test assesses performance of eight tasks that simulate ADL. ${ }^{69}$

\section{Measuring Cognitive Functioning}

Cognitive impairment is common in elderly patients, adversely affects functional status, and is most often due to dementia or delirium. Infectious diseases are among the most common causes of delirium. Cognitive function is assessed through use of questionnaires including ADL items, and brief tests of mental status. ${ }^{59}$ The Mini-Mental State Examination is a 30 -item instrument that screens several cognitive domains and is most useful in non-hospitalized patients. $^{70}$ The Short Portable Mental Status Questionnaire, a 10-item instrument, is a practical instrument for use in hospitalized patients. ${ }^{71}$ The Confusion Assessment
Method is used to diagnose delirium in studies of hospitalized patients. It assesses patients for an acute change in mental status and fluctuating course, inattention, disorganized thinking and altered level of consciousness. ${ }^{72}$

\section{Measuring Depression}

Depressive symptoms are predictive of functional decline and increased risk of mortality. The short-form Geriatric Depression Scale is a 15 -item scale that can be completed as a self-report or through interview of patients with normal cognition. ${ }^{73}$ The Center for Epidemiologic Studies Depression scale contains 20-items and is used in studies of depression in community-based samples. (www.chcr.brown. edu/pcoc/cesdscale.pdf)

\section{Functional status in Long-term Care Residents}

In institutional long-term care the federally mandated Minimum Data Set (MDS) provides patient data including demographic characteristics, dementia severity, co-morbidity, and measures of physical disability. ADL summary scales derived from the MDS can be used in health services research. ${ }^{74}$

\section{Co-morbidity measures}

Many measures of co-morbidity exist and are used to adjust for the effects of chronic disease on outcomes of therapy. The Charlson co-morbidity index, which weights chronic diseases with a point score, is widely used in studies of ambulatory and hospitalized elderly patients ${ }^{75}$, and can be adapted to use for infectious diseases research.

Overall recommendations for measuring functional status Recommended functional assessment measures are summarized in Table 1. Specific tools are selected based on study goals. For example, general instruments provide breadth of information that is most useful in community based studies or large populations whereas more specific measures such as ADL items are useful in hospitalized or long-term care patients.

\section{EXISTING LITERATURE ON FUNCTIONAL STATUS AND RESPIRATORY TRACT INFECTION IN OLDER ADULTS}

Because the elderly frequently have multiple risk factors for disease acquisition or poor outcomes, a multivariable model is best suited to studying infectious episodes in older adults ${ }^{11,12}$. However, adequately designed clinical research regarding the relationship between functional status and infection in older adults is limited. The majority of the literature, not surprisingly, focuses on respiratory infections, one of the greatest threats to the health of older adults ${ }^{76}$, and a brief review of the data are presented here as an example of the current literature. In addition, nearly all studies have been performed in long-term care residents raising several issues regarding power to detect a difference and generalizability.

Studies can be broadly categorized into one of two groups, the assessment of functional status: 1) as a risk factor for infection, or 2) as an outcome after an infectious episode. Relatively few studies exist in the former category, 
Table 1. Some Recommended Measures of Functional Status. (Measures for which the range of scores is marked with an * indicate higher score $=$ better functional status. Unmarked ranges indicate higher score $=$ worse functional status

\begin{tabular}{|c|c|c|c|}
\hline Domain & Measure & Example/Comment & Range of Scores \\
\hline Health-related quality of life & Short-form 36 (SF-36) & $\begin{array}{l}\text { Community based study of a } \\
\text { chronic infection and treatment } \\
\text { (for example, osteomyelitis, } \\
\text { endocarditis) }\end{array}$ & $0-100 *$ \\
\hline $\begin{array}{l}\text { Basic activities of daily } \\
\text { living (ADL) }\end{array}$ & $\begin{array}{l}\text { Index of ADL; physical } \\
\text { functioning subscale of SF-36 }\end{array}$ & $\begin{array}{l}\text { Predictors and outcomes of } \\
\text { nosocomial pneumonia in } \\
\text { nursing home patients }\end{array}$ & $\begin{array}{l}\text { ADL: } 0-6^{*} ; \\
\text { SF-36: } 0-100^{*}\end{array}$ \\
\hline Instrumental ADL (IADL) & $\begin{array}{l}\text { Lawton IADL; OARS (Older } \\
\text { American Resources and } \\
\text { Services) IADL }\end{array}$ & $\begin{array}{l}\text { Follow-up of patients after } \\
\text { hospitalization for abdominal } \\
\text { wound infection }\end{array}$ & $0-7^{*}$ \\
\hline Mobility & $\begin{array}{l}\text { Timed Up and Go Test Short } \\
\text { Physical Performance Battery } \\
\text { (SPPB) }\end{array}$ & $\begin{array}{l}\text { Study of physical limitations } \\
\text { after systemic infection; the } \\
\text { SPPB for community based } \\
\text { prospective studies to define } \\
\text { quality of life after treatment } \\
\text { of infections }\end{array}$ & $\begin{array}{l}\text { TUG: } 0-30 \text { seconds; } \\
\text { SPPB: } 0-12 *\end{array}$ \\
\hline Cognition & $\begin{array}{l}\text { Mini-Mental State Examination } \\
\text { (MMSE); Short Portable Mental } \\
\text { Status Questionnaire (SPMSQ) }\end{array}$ & $\begin{array}{l}\text { Cognitive function in patients } \\
\text { with delirium secondary to } \\
\text { infection }\end{array}$ & $\begin{array}{l}\text { MMSE: } 0-30^{*} ; \\
\text { SPMSQ: } 0-10\end{array}$ \\
\hline Delirium & Confusion Assessment Method & $\begin{array}{l}\text { Incidence of delirium } \\
\text { associated with acute } \\
\text { infections }\end{array}$ & $0-4$ \\
\hline Depression & $\begin{array}{l}\text { 15-item Geriatric Depression } \\
\text { Scale }\end{array}$ & $\begin{array}{l}\text { Study of neuropsychiatric } \\
\text { effects of chronic infection }\end{array}$ & $0-15$ \\
\hline Long-term Care Residents & Minimum Data Set (MDS) & $\begin{array}{l}\text { ADL summary scales can } \\
\text { be derived from the MDS }\end{array}$ & $0-10^{*}$ \\
\hline Co-morbidity & Charlson Co-morbidity Index & $\begin{array}{l}\text { Assigns points for underlying } \\
\text { co-morbidities and allows } \\
\text { adjustment for their effects }\end{array}$ & $0-\geq 5$ \\
\hline
\end{tabular}

but one prospective cohort study, among 475 residents of 5 nursing homes, demonstrated that immobility (defined in the study as dependency in bathing, dressing, transferring, going to the toilet, continence, and feeding) was an independent risk factor for lower respiratory tract infection ${ }^{77}$.

Both prospective and retrospective studies have addressed functional status as an outcome after infection with mixed results. For example, a prospective study in a Veteran's Affairs facility examined the clinical course of patients with pneumonia. The majority of patients who survived did not show a significant reduction in functional status, as measured by an ADL score every 3 months for one year ${ }^{58}$. This was likely due to a floor effect (limited ability to detect a decline due to limits of the scale itself despite true declines in function), since the median ADL score before infection was 17 (of a possible 18). This study did demonstrate an association between worse functional status and increased mortality. In contrast, in a retrospective cohort study designed to assess predictors of mortality in 378 nursing home residents with pneumonia, poor functional status (ADL score $>14$ ) was not associated with risk of death ${ }^{78}$.

A prospective cohort study of 781 episodes of lower respiratory infection in 1044 LTC residents revealed an incidence of functional status decline of $29 \%$, defined as a 3 point increase on the Minimum Data Set (MDS) activities of daily living (ADL) long form scale ${ }^{74}$. In multivariable modeling, variables associated with functional decline included both decline in self-performance of toilet use in the 24 hours prior to evaluation and baseline ADL score. Addition of treatment variables to the model showed that initial hospitalization was also associated with ADL decline. Residents with decline in functional status at 30 days were less likely to recover to their baseline status at 90 days.

In a retrospective cohort study set in an academic longterm care facility, 16 of $65(25 \%)$ residents hospitalized had worsening functional status at 2 months while 47 of 243 $(19 \%)$ residents had worsening function (defined by increased dependency) after pneumonia ${ }^{79}$. No comparison was done however with residents who did not have pneumonia. A prospective study that did compare nursing home residents with pneumonia vs. those without ${ }^{77}$ demonstrated residents with pneumonia or other lower respiratory infections were no more likely to have a deterioration in functional status than in those in whom infection did not develop. The rate of functional decline was actually greater prior to the infection than after for residents with pneumonia. A possible explanation might again be a floor effect; declines in function may not be detectable in previously impaired hosts using the instruments employed.

In a retrospective study of 116 nursing home residents who developed influenza-like illness were compared to 127 

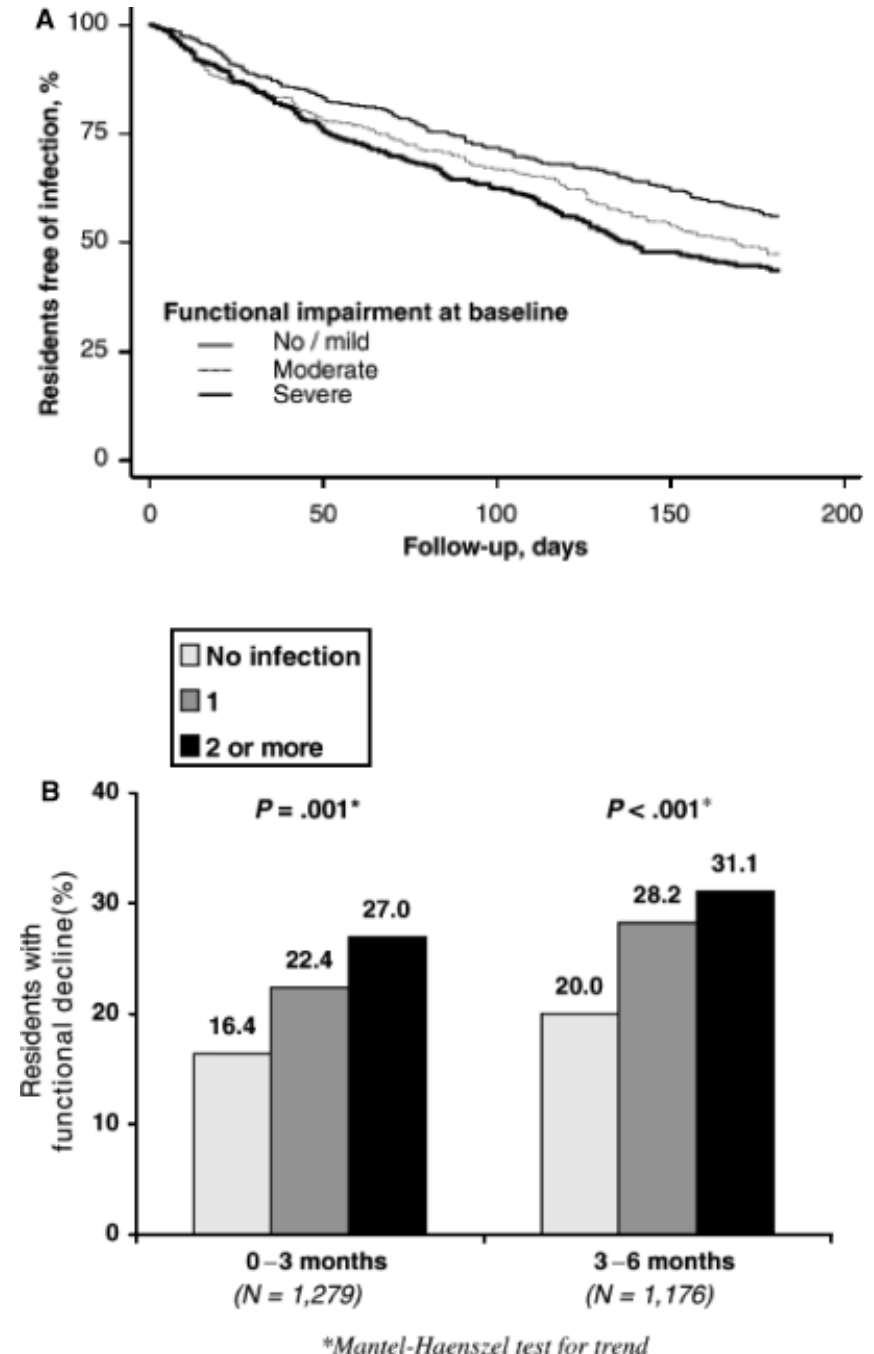

Figure 3. (A) Risk of infection over six months in Long-Term Care residents stratified by baseline functional status (Reprinted from (80) with permission). (B) Risk of functional decline following 0,1 or $\geq 2$ infections over six months in Long-Term Care residents (Reprinted from (80) with permission).

residents randomly selected residents without influenza illness ${ }^{80}$. Significantly more cases $(25 \%)$ than control subjects $(16 \%)$ experienced a decline in functional status ${ }^{80}$.

Finally, one large, prospective trial examined functional status both as a risk factor and outcome variable in older adults, and suggests there is a strong interaction between these two factors ${ }^{81}$. Functional status was assessed in LTC residents age 65 and older $(n=1324)$ at baseline, 3 months and 6 months. Baseline moderate impairment of functional status (defined as an ADL score of 2-4) or severe impairment (ADL score $>4$ ) were independent risk factors for infection (Figure 3A). Further, while functional decline occurred on average for all study subjects, the decline was more rapid in those that experienced an infectious episode, and the "change in slope" toward a more rapid loss of function was temporally associated with a "trigger episode" of infection. Further, there was a dose-response with an increased risk of functional decline as the number of infectious episodes increased from $0 \rightarrow 1 \rightarrow 2$ or more (Figure 3B).
As indicated above, the major focus on functional status has been in the long-term care setting. To our knowledge, there are no large studies evaluating functional status longitudinally in older adults treated in the community for infection or admitted with infections from the community to acute care hospitals. Furthermore, there is a paucity of information about the effect of choice, timing or duration of anti-infective agents on functional status, and very limited data on physical therapy, nutritional supplements or other interventions to reduce disability during or after an episode of infection. Clearly, more research needs to be performed in this area, and studies must be designed to answer the questions of importance in caring for older adults.

\section{CONCLUSIONS/RECOMMENDATIONS}

1. The population of aged adults is growing rapidly, and infectious diseases in the elderly present specific challenges for clinical investigation. Age itself is not a surrogate marker for issues in geriatrics and should not be considered an adequate assessment of functional status, cognitive capacity, co-morbidity or frailty.

2. Numerous studies indicate that infections and other illnesses adversely impact the functional status of older adults. Mechanistic data support a relationship between infection/inflammation and age-associated functional decline.

3. Research of infectious syndromes in the elderly should include not only well-accepted clinical and microbiologic parameters, but measures of functional status, cognitive integrity, psychological burden, quality of life and discharge placement needs. This may be facilitated by multi-disciplinary teams of researchers with both Infectious Diseases and Geriatrics experience and expertise.

4. Functional parameters can be assessed by well validated instruments and should be evaluated both as risk factors and outcomes of interest. The quality of clinical research in older adults depends on inclusion of these parameters when investigating infectious syndromes, and should be encouraged by journal editors, scientific program reviewers, and regulatory agencies in order to provide meaningful information for clinicians who care for the growing population of older adults.

\section{ACKNOWLEDGEMENTS}

The authors wish to thank the members of the Infections in Older Adults Interest Group of The Infectious Diseases Society of America for their helpful comments and support of the concepts in this manuscript. No financial support was obtained for this work.

\section{REFERENCES}

1. Kinsella K, Velkoff VA. An Aging World: International Population Reports. Washington, DC: US Census Bureau, Series P95/01-1, US Government Printing Office, 2001.

2. Yoshikawa TT. Epidemiology and unique aspects of aging and infectious diseases. Clin Infect Dis 2000;30:931-3.

3. Yoshikawa TT, Norman DC, (eds). Infectious Disease in the Aging. A Clinical Handbook. Totowa, New Jersey: Humana Press, 2001.

4. High KP. Infection as a Cause of Morbidity and Mortality in the Aged. Aging Res Rev 2004;3:1-14. 
5. Lyons AS, Petrucelli RJ II In Abrams Harry N., ed. Medicine. An Illustrated History. New York: 1978.

6. U.S. Dept. of Health \& Human Services, Public Health Service, National Center for Health Statistics. Health United States 1985. DHHS Pub. No. (PHS) 86-1232. Hyattsville, MD.

7. Centers for Disease Control and Prevention. Trends in Aging-United States and worldwide. MMWR 2003;52:101-105.

8. Kemper P, Murtaugh CM. Lifetime use of nursing home care. N Engl J Med 1991;324:595-600.

9. Khanna KV, Markham RB. A perspective on cellular immunity in the elderly. Clin Infect Dis 1999;28:710-3.

10. Bentley DW, Bradley S, High K, Schoenbaum S, Taler G, Yoshikawa TT. Practice guidelines for evaluation of fever and infection in long-term care facilities. Clin Infect Dis 2000;31:640-53.

11. Loeb MB. Community-acquired pneumonia in older people: the need for a broader perspective. J Am Geriatr Soc 2003;51:539-43.

12. Loeb MB. Use of a broader determinants of health model for communityacquired pneumonia in seniors. Clin Infect Dis 2004;38:1293-7.

13. Roghmann MC, Warner J, Mackowiak PA. The relationship between age and fever magnitude. Am J Med Sci 2001;322:68-70.

14. Castle SC, Norman DC, Yeh M, Miller D, Yoshikawa TT. Fever response in elderly nursing home residents: are the older truly colder? J Am Geriatr Soc 1991;39:853-7.

15. Castle SC, Yeh M, Toledo S, Yoshikawa TT, Norman DC. Lowering the temperature criterion improves detection of infection in nursing home residents. Aging Immunol Infect Dis 1993;4:67-76.

16. Berman P, Hogan DB, Fox RA. The atypical presentation of infection in old age. Age Aging 1986;15:230-4.

17. Kirkland J, Lye M, Goddard F, Vargas E, Davies I. Plasma arginine vasopression in arginine-vasopressin secretion. Miner Electrolyte Metab 1993;19:32-5.

18. Loeb M, Bentley DW, Bradley $S$ et al. Development of minimum criteria for the initiation of antibiotics in residents of long-term-care facilities: Results of a consensus conference. Infect Control Hosp Epidemiol 2001;22:120-4.

19. Fein A. Pneumonia in the elderly: Overview of diagnostic and therapeutic approaches. Clin Infect Dis 1999;28:726-9.

20. Meyers RR, Sherman E, Mendelson $\mathrm{MH}$ et al. Bloodstream infections in the elderly. Am J Med 1989;86:379-84.

21. Selton-Suty C, Hoen B, Grentzinger A et al. Clinical and bacteriological characteristics of infective endocarditis in the elderly. Heart 1997;77:260-63.

22. Inungu JN, Mokotoff ED, Kent JB. Characteristics of HIV infection in patients fifty years or older in Michigan. AIDS Patient Care and Stds 2001;15:567-73.

23. Walston MA, McBurnie A, Newman A et al. Frailty and activation of the inflammation and coagulation systems with and without clinical comorbidities: Results from the Cardiovascular Health Study. Arch Intern Med 2002; 162:2333-41.

24. Bruunsgaard H, Andersen-Ranberg K, Hjelmborg JvB, Pedersen BK, and Jeune B. Elevated Levels of Tumor Necrosis Factor Alpha and Mortality in Centenarians. Am J Med 2003;115:278-283.

25. Bruunsgaard H., Ladelund S, Pedersen AN, Schroll M, Jørgensen T, and Pedersen BK. Predicting death from tumor necrosis factor-alpha and interleukin6 in 80-year-old people. Clin Exp Immunol 2003;132:24-31.

26. Pennix BWJH, Kritchevsky SB, Newman AB et al. Inflammatory Markers and Incident Mobility Limitation in the Elderly. J Am Geriatr Soc In press.

27. Taaffe DR, Harris TB, Ferrucci L, Rowe J, and Seeman TE. Cross-sectional and Prospective Relationships of Interleukin-6 and C-Reactive Protein With Physical Performance in Elderly Persons: MacArthur Studies of Successful Aging. J Gerontol: MEDICAL SCIENCES 2000;55A(12):M709-M715.

28. Ferrucci L, and Guralnik JM. Inflammation, Hormones, and Body Composition at a Crossroad. Am J Med 2003;115:501-502.

29. Ferucci L, Guralnik JM, Cavazzini C et al. The frailty syndrome: a critical issue in geriatric oncology. Critical Reviews in Oncology/Hematology 2003;46: 127-137.

30. Ferrucci L, Pennix BWJH, Bolpato S et al. Change in Muscle Strength Explains Accelerated Decline of Physical Function in Older Women With High Interleukin-6 Serum Levels. J Am Geriatr Soc 2002;50:1947-1954.

31. Cappola AR, Xue QL, Ferrucci L, Guralnik JM, Volpato S, and Fried LP. Insulin-Like Growth Factor 1 and Interleukin-6 Contribute Synergistically to Disability and Mortality in Older Women. J Clin Endocrinol Metab May 2003;88(5):2019-2025.

32. Barbieri M, Ferrucci L, Ragno E et al. Chronic inflammation and the effect of IGF-1 on muscle strength and power in older persons. Am J Physiol Endocrinol Metab 2003;284:E481-E487.

33. Fried LP, Walston J. Frailty and Failure to Thrive. In Hazzard, Blass, Ettinger Jr, Halter, Ouslander, eds. Principles of Geriatric Medicine and Gerontology, $5^{\text {th }}$ edition. NY: McGraw-Hill, 2003. 1487-1502.

34. Castle SC. Clinical relevance of age-related immune dysfunction. Clin Infect Dis 2000;31:578-85.
35. Bruunsgaard H, Skinhøj P, Qvist J, Pedersen BK. Elderly Humans Show Prolonged In Vivo Inflammatory Activity during Pneumococcal Infections. The Journal of Infectious Diseases 1999;180:551-554.

36. Krabbe KS, Bruunsgaard H, Hansen CM et al. Ageing Is Associated with a Prolonged Fever Response in Human Endotoxemia. Clinical and Diagnostic Laboratory Immunology Mar. 2001; Vol 8, No. 2:333-338.

37. Marik PE, Zaloga GP for the NORASEPT II Study Investigators. North American Sepsis Trial II. The effect of aging on circulating levels of proinflammatory cytokines during septic shock. J Am Geriatr Soc 2001 Jan;49(1): 5-9.

38. Priø TK, Bruunsbard H, Røge B, Pedersen BK. Asymptomatic bacteriuria in elderly humans is associated with increased levels of circulating TNF receptors and elevated numbers of neutrophils. Experimental Gerontology 2002;37: 693-699.

39. Glaser R, Robles TF, Sheriden J, Malarkey WB, Kiecolt-Glaser JK. Mild Depressive Symptoms Are Associated With Amplified and Prolonged Inflammatory Responses After Influenza Virus Vaccination in Older Adults. Arch Gen Psychiatry 2003;60:1009-1014.

40. Cohen HJ, Harris T, Pieper CF. Coagulation and activation of inflammatory pathways in the development of functional decline and mortality in the elderly. Am J Med 2003;114:180-7.

41. Delbono O. Molecular mechanisms and therapeutics of the deficit in specific force in ageing skeletal muscle. Biogerontology 2002;3:265-270.

42. Rantanen T, Guralnik JM, Foley D et al. Midlife hand grip strength as a predictor of old age disability. JAMA 1999;281:558-60.

43. Visser M, Pahor M, Taaffe DR et al. Relationship of inteleukin-6 and tumor necrosis factor-alpha with muscle mass and muscle strength in elderly men and women: The Health ABC Study. J Gerontol A Biol Sci Med Sci 2002;57: M326-M332.

44. Goodman MN. Tumor necrosis factor induces skeletal muscle protein breakdown in rats. Am J Physiol 1991;260:E727-E730.

45. Goodman MN. Interleukin-6 induces skeletal muscle protein breakdown in rats. Proc Soc Exp Biol Med 1994;205:182-85.

46. Tayek JA. Effects of tumor necrosis factor alpha on skeletal muscle amino acid metabolism studied in-vivo. J Am Coll Nutr 1996;15:164-68.

47. Garcia-Martinez C, Lopez-Soriano FJ, Argiles JM. Acute treatment with tumour necrosis factor-alpha induces changes in protein metabolism in rat skeletal muscle. Mol Cell Biochem 1993;125:11-18.

48. Ohiishi K, Katayama N, Shiku H, Varnun-Finney B, Bernstein ID. Notch signaling in hematopoiesis. Seminars in Cell \& Developmental Biology 14 2003, 143-150.

49. Cheng P, Nefedova Y, Miele L, Osborne BA, Gabrilovich D. Notch signaling is necessary but not sufficient for differentiation of dendritic cells. Blood 2003; Vol 102(12):3980-3988.

50. Conboy IM, Conboy MJ, Smythe GM, Rando TA. Notch-Mediated Restoration of Regenerative Potential to Aged Muscle. Science Nov. 2003; Vol 302: 1575-1577.

51. Grounds MD. Reasons for the degeneration of ageing skeletal muscle: A central role for IGF-1 signaling. Biogerontology 2002;3:19-24.

52. Frost RA, Lang CH. Regulation of insulin-like growth factor-1 in skeletal muscle and muscle cells. Minerva Endocrinol 2003;28(1):53-73.

53. Frost RA, Nystrom GJ, Lang CH. Tumor Necrosis Factor- $\alpha$ Decreases InsulinLike Growth Factor-I Messenger Ribonucleic Acid Expression in C2C12 Myoblasts via a Jun N-Terminal Kinase Pathway. Encocrinology 2002;144(5): 1770-1779.

54. Barker WH, Borisute H, Cox C. A study of the impact of influenza on the functional status of frail older people. Arch Intern Med 1998;158:645-650.

55. Walter LC, Brand RJ, Counsell SR, Palmer RM, Landefeld CS, Fortinsky RH, Covinsky KE. Development and validation of a prognostic index for 1-year mortality in older adults after hospitalization. JAMA 2001;285:2987-2994.

56. Chuang KH, Covinsky KE, Sands LP et al. Diagnosis related group adjusted hospital costs are higher in older medical patients with lower functional status. J Am Geriatr Soc 2003;51:1729-1734.

57. Deulofeu F, Cervello B, Capell S, Mari C, Mercade V. Predictors of mortality in patients with bacteremia: The importance of functional status. J Am Geriatr Soc 1998;46:14-8.

58. Muder RR, Brennen C, Swenson DL et al. Pneumonia in the long-term care facility. A prospective study of outcome. Arch Intern Med 1996;156: 2365-2370.

59. Gallo JJ, Fulmer T, Paveza GJ, Reichel W. Handbook of Geriatric Assessment, $3^{\text {rd }}$ ed. Gaithersburg, MD: Aspen Publishers, Inc, 2000.

60. Ware JE, Sherbourne CD. The MOS 36-item short-form health survey (SF-36). I. Conceptual framework and item selection. Med Care 1992;30:473-483.

61. Katz S Ford AB, Moskowitz RW et al. Studies of illness in the aged: The index of ADL. JAMA 1963;185:914-919.

62. Lawton MP, Brody EM. Assessment of older people: Self-maintaining and instrumental activities of daily living. Gerontologist 1969;9:179-186. 
63. The Older American Resources and Services (OARS) Methodology. Multidimensional Functional Assessment Questionnaire, $2^{\text {nd }}$ ed. Durham, NC: Duke University Center for the Study of Aging and Human Development, 1978. 169-170.

64. Mahoney FI, Barthel DW. Functional assessment: The Barthel index. MD Med J 1965;14:61-65.

65. Hamilton BB, Granger CV, Sherwin FS et al. A uniform national data system for medical rehabilitation. In: Fuhrer MJ, ed. Rehabilitation Outcomes: Analysis and Measurement. Baltimore, Md: Brooks, 1987.

66. Guralnik JM, Ferruci L, Simonsick EM et al. Lower-extremity function in persons over the age of 70 years as a predictor of subsequent disability. $\mathrm{N} \mathrm{Engl}$ J Med 1995;332:556-561.

67. Podsiadlo D, Richardson S. The Timed "Up and Go": A test of basic functional mobility for frail elderly persons. J Am Geriatr Soc 1991;39:142-148.

68. Tinetti ME. Performance-oriented assessment of mobility problems in elderly patients. J Am Geriatr Soc 1986;34:119-126.

69. Reuben DB, Siu AL. An objective measure of physical function of elderly outpatients: The Physical Performance Test. J Am Geriatr Soc 1990;38: 1105-1112.

70. Folstein MF, Folstein SE, McHugh PR “Mini-mental state”. A practical method for grading the cognitive state of patients for the clinician. J Psychiatr Res 1975;12:189-198.

71. Pfeiffer E. A short portable mental status questionnaire for the assessment of organic brain deficit in elderly patients. J Am Geriatr Soc 1975;23:433-441.

72. Inouye SK, van Dyck CH, Alessi CA, Balkin S, Siegal AP, Horwitz RI. Clarifying confusion: The confusion assessment method. A new method for detection of delirium. Ann Intern Med 1990;113:941-8.
73. Sheikh JI, Brink TL, Rose TL et al. Development and validation of a geriatric depression rating scale: A preliminary report. Clin Gerontol 1986;5:165-172.

74. Binder EF, Kruse RL, Sherman AK, Madsen R, Zweig SC, D’Agostino R, Mehr DR. Predictors of short-term functional decline in survivors of nursing homeacquired lower respiratory tract infection. J Gerontol A Biol Sci Med Sci 2003;58:60-7.

75. Charlson ME, Pompei P, Ales KL, MacKenzie CR. A new method of classifying prognostic comorbidity in longitudinal studies: Development and validation. J Chronic Dis 1987; 40:373-83.

76. Marrie TJ. Community-acquired pneumonia in the elderly. Clin Infect Dis 2000;31:1066-78.

77. Loeb M, McGeer A, McArthur M, Walter S, Simor A. Risk factors for pneumonia and other lower respiratory tract infections in elderly residents of longterm care facilities. Archives of Internal Medicine 1999;159:2058-2064.

78. Naughton BJ, Mylotte JM, Tayara A. Outcome of nursing home-acquired pneumonia: Derivation and application of a practical model to predict 30 day mortality. J Am Geriatr Soc 2000;48:1292-9.

79. Fried TR, Gillick MR, Lipsitz Short-term functional outcomes of long-term care residents with pneumonia reated with and without hospital transfer. JAGS 1997;45:302-306.

80. Barker WH, Borisute H, Cox C. A study of the impact of influenza on the functional status of frail older people. Arch Intern Med 1998;158:645-50.

81. Bula CJ, Ghiraldi G, Weitlisbach V, Petnignat C, Francioli P. Infections and functional impairment in nursing home residents: A reciprocal relationship. J Am Geriatr Soc 2004;52:700-6.

82. Walston J. Frailty-the search for underlying causes. Sci Aging Knowledge Environ. 2004 Jan 28;2004(4):pe4. 